\title{
Pneumonia associated with rising cytomegalovirus antibody titres in a healthy adult
}

\author{
STEVEN IDELL, MICHELE JOHNSON, LOUANNE BEAUREGARD, \\ NORMAN LEARNER
}

\author{
From the Departments of Medicine and Radiology, Temple University School of Medicine, Philadelphia, \\ Pennsylvania, USA
}

Cytomegalovirus infection in otherwise normal adults is characterised by a febrile syndrome associated with atypical lymphocytosis and negative heterophil agglutination.' Radiographic evidence of cytomegalovirus infection pneumonia is not infrequently seen in association with the immunocompromised state..$^{-5}$ We here describe a 21 year old man with no antecedent medical illnesses who presented with an acute febrile illness accompanied by pneumonia, a rising titre of antibody to cytomegalovirus infection, and an eosinophilic pleural effusion.

\section{Case report}

A 21 year old man, previously in good health, was admitted to the Temple University Hospital, Philadelphia, for elective repair of a right inguinal hernia. On admission he complained of right sided chest pain which radiated to the left scapula and worsened with deep inspiration. Anorexia and malaise developed without associated chills, sore throat, or myalagia. The temperature was $38.3^{\circ} \mathrm{C}$ and he did not appear jaundiced. Painless cervical adenopathy was noted. Cardiac examination showed nothing remarkable. Decreased breath sounds were noted at the right base. The liver was not definitely enlarged but was tender on palpation. The spleen was not palpable. A right inguinal hernia was present.

The white blood cell count was $11.6 \times 10 \% / 1$ with a differential count of $30 \%$ polymorphonuclear leucocytes, $15 \%$ atypical lymphocytes, $5 \%$ monocytes and $50 \%$ lymphocytes. A monospot test gave a negative result. The alkaline phosphatase activity was 153 IU/l (normal 30-100 IU/l), lactic dehydrogenase was 306 IU/I (normal 100-225 IU/1), and aspartic transaminase was 59 IU/l (normal 10-50 IU/1). An antinuclear antibody test was positive at a titre of $1 / 640$ with a speckled pattern. A chest radiograph 10 days after admission showed a nodular left lower lobe infiltrate associated with small bilateral pleural effusions (fig). The chest radiograph obtained on admission, at the onset of the patient's symptoms, had been normal. Thoracentesis was performed. The pleural fluid white cell count was

Address for reprint requests: Dr Steven Idell, Pulmonary Disease Section, Temple University Hospital, Philadelphia, Pennsylvania 19140, USA

Accepted 19 August 1983
$3 \times 10^{6}$ cells/l with $6 \%$ monocytes, $6 \%$ basophils, $60 \%$ eosinophils, $21 \%$ lymphocytes, and $7 \%$ polymorphonuclear leucocytes on differential count. The red cell count was $7.5 \times 10^{7} / 1$. The pleural fluid protein concentration was $52 \mathrm{~g} / \mathrm{l}$, glucose $110 \mathrm{mg} / \mathrm{dl}(6 \mathrm{mmol} / \mathrm{l})$ and lactate dehydrogenase $400 \mathrm{IU} / \mathrm{l}$. The arterial blood oxygen tension was $82 \mathrm{mmHg}(10.9 \mathrm{kPa})$ with the patient breathing air. Ventilation-perfusion lung scintigraphy showed a nonsegmental defect at the right base, which was interpreted as being unlikely to be due to pulmonary embolism. A tuberculin test gave a negative result. Pleural fluid culture was negative for viral and bacterial pathogens and cytological examination gave negative results. Blood, sputum, and urine cultures were negative for bacterial pathogens. The serum cytomegalovirus infection titre by indirect immunofluorescence was 1/512 in the acute phase and rose to $1: 16384$ five weeks after the onset of the patient's illness, at which time he was symptom free and the chest radiograph showed that the pulmonary inflitrate and pleural fluid had cleared. A repeat test for antinuclear antibody was negative. The patient remains in good health after 18 months of follow up.

\section{Discussion}

Cytomegalovirus infection pneumonia is most commonly seen in the compromised host. The most common cause of viral pneumonia in immunocompromised patients is cytomegalovirus infection, which has a predilection for recipients of organ transplants. ${ }^{2}$ In this setting pulmonary manifestations range from peribronchovascular consolidation or miliary nodules to diffuse consolidation. ${ }^{3}$ Rare cases of unilateral consolidation ${ }^{4}$ have been described and there has been a single case report of necropsy proved cytomegalovirus infection pneumonia in a compromised patient presenting as a solitary pulmonary nodule. ${ }^{5}$ Although radiological evidence of cytomegalovirus pneumonia in the normal host is unusual, the resolution of the abnormalities as the clinical features subsided, together with the rise in cytomegalovirus infection titre, makes cytomegalovirus pneumonia the most likely cause of the acute illness in our patient.

The course of spontaneous cytomegalovirus infection in previously healthy adults is usually that of a mild illness characterised by malaise, fever, atypical lymphocytosis, abnormal results in liver function tests, and negative heterophil agglutination.' Exudative pharyngitis is typi- 

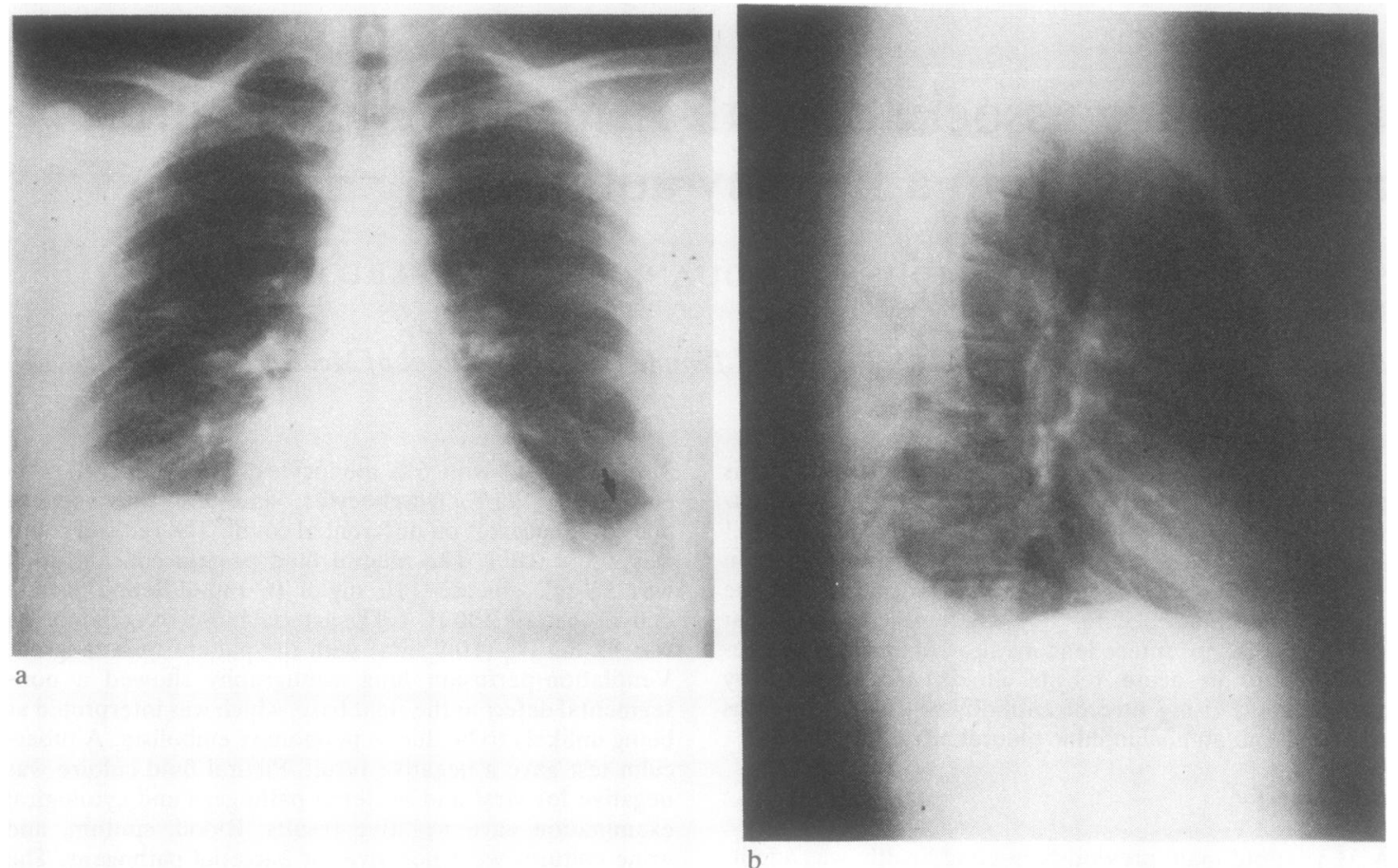

(a) Posteroanterior and (b) lateral radiographs of the chest showing presence of small bilateral pleural effusions. A parenchymal nodular infiltrate is present in the left lower lobe at the costophrenic angle.

cally absent. ${ }^{1-6}$ Urine cultures were negative for cytomegalovirus infection early in the illness in one third of patients reported by Jordan et al,' and Klemola et al ${ }^{6}$ reported positive virological identification in only $25 \%$ of such patients.

Pleural fluid eosinophilia has been found with infectious processes but among viruses only influenza has been convincingly associated.7 Additional cases of presumed viral infection have been described but have lacked definitive identification. ${ }^{6}$ This case probably represents the first documentation of acute cytomegalovirus infection pneumonia and eosinophilic pleural effusion in an otherwise healthy adult.

We are indebted to the staff of the immunology laboratory of Temple University Health Sciences Center for having performed the cytomegalovirus infection antibody testing and Ms Anna Velez and Ms Norma Register for assistance in preparing the manuscript.

\section{References}

1 Jordan MC, Rousseau WE, Stewart JD, Noble GR, Chin TYD. Spontaneous cytomegalovirus mononucleosis. Ann Intern Med 1973;79:153-60.

${ }^{2}$ Fanta $\mathrm{CH}$, Pennington JE. Fever and infiltrates in immunocompromised hosts. Clin Chest Med 1981;2:19-39.

${ }^{3}$ Greene R. Opportunistic pneumonias. Sem Roentgenol 1980;15:50-72.

4 Rubin RH, Cosimi AB, Tolkoff-Rubin NE, et al. Infectious syndromes attributable to cytomegalovirus and their significance among renal transplant recipients. Transplant 1977;24:458-64.

${ }^{5}$ Ravin CE, Smith GW, Ahern MJ, et al. Cytomegalovirus present ing as a solitary pulmonary nodule. Chest 1971;71:220-4.

- Klemola E, VonSasen R, Wager O, et al. Cytomegalovirus mononucleosis in previously healthy individuals. Ann Intern Med 1969;71:11-9.

' Bower G. Eosinophilic pleural effusion. Am Rev Respir Dis 1967;95:746-51. 